\title{
Student Management And Human Intelligence Skills Enhanced Through Community Service
}

Stefanie Denise Wilson, University of Hawaii-West Oahu, USA

\begin{abstract}
Based on years of human intelligence research conducted by Howard Gardner and results from a quantitative research study supporting Gardner's research collected from a sample of 205 faculty within the United States, the researcher examined students that are actively engaged in community service experiences and their approaches to reframing their intelligences and enhancing their unique learning, problem-solving, and decision-making skills. Students who reach beyond the class or virtual rooms of academia and become actively involved in community service organizations gain organizational experiences that sharpen their management and human intelligence skills to equip them with operating in a competitive world of constant organizational change.
\end{abstract}

Keywords: Human Intelligence; Multiple Intelligence; Community Service; Management Skills

\section{INTRODUCTION}

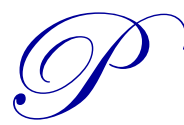

roviding stellar community service is the mission of many organizations throughout the world comprised of people that become bonded to achieve something greater than self. "The word "community" evokes images of democracy, diversity, cooperation, inclusion, and common purpose (Manning and Curtis, 2012, p.83). Community fosters building genuine relationships as knowledge and ideas are shared. Service, simply put, is the "aid and assistance provided to others; concern for the well-being and the best interest of another person or group" (Manning and Curtis, 2012, p.490). This paper addresses how student management and human intelligence skills are enhanced and applied through community service endeavors.

\section{GARDNER'S MULTIPLE INTELLIGENCES}

There is agreement among theorists that multiple intelligences are significant to effective leadership. Psychologist, author, and Professor of Neurology at Boston University's Medical School and Professor of Education at Harvard's Graduate School, Howard Gardner, is considered a pioneer for exploring the sources of evidence regarding a list of human intelligences known as multiple intelligence (MI) theory. "Almost eighty years after the first intelligence tests were developed, Gardner challenged the notion that intelligence is something that can be objectively measured and reduced to a single quotient or score" (Stanford, 2003, p.80). Gardner's original list includes seven multiple human intelligences: 1) verbal-linguistic, 2) visual-spatial, 3) logical-mathematical, 4) bodily-kinesthetic, 5) musical-rhythmic, 6) interpersonal, and 7) intrapersonal (Manning \& Curtis, 2012). follows:

Manning and Curtis (2012) described Gardner's seven types of multiple intelligence characteristics as

1. Verbal-linguistic individuals are prolific readers, writers, and are great at memorizing names and places.

2. Musical-rhythmic people are sensitive to rhythm and sounds, and are best at thinking and expressing in musical form.

3. Logical-mathematical individuals are skilled with numbers and are great at reasoning, logic and problemsolving. 
4. Visual-spatial individuals think in terms of physical space and are good at creating, building and designing things.

5. Bodily-kinesthetic individuals have a unique ability to use body movements in learning and expressing as they are good at physical activities.

6. Intrapersonal individuals have the ability to understand themselves, their interest and goals, and are great at following instincts, pursing their dreams, and being unique.

7. Interpersonal individuals embody the ability to understand and interact with people as they are good at leading others, organizing, communicating, manipulating, and mediating conflicts.

"Gardner believed that the primary measurement of intelligence (e.g. IQ tests) was too narrow and limiting, so he proposed his theory of multiple intelligences" (Johnson \& White, 2002, p.2). "Fiedler, in his Cognitive Resources Theory, emphasizes that both intelligence (IQ) and experience are important to effective leadership and he acknowledges that different forms of intelligence are part of the leader's cognitive resources" (Riggio et al., 2002 , p. 242). Fiedler also gives credence to non-IQ forms of intelligence; namely, social and emotional intelligence and its contribution to a leader's experience (Riggio et al.).

\section{MULTIPLE INTELLIGENCES AND AGE}

The research findings on age and the nature of intelligence have surfaced several important implications. The notion that intellectual ability declines during adulthood is a myth (Sternberg \& Grigorenko, 2003). "There are numerous discussions of the genetics and biology [of intelligence]. In these formulations, an individual is endowed with a certain amount [of intelligence] at conception. The individual presumably carries this level [of intelligence] through infancy, childhood, and adulthood" (Ackerman \& Lohman, 2003, p.279). This indicates that the level of intelligence throughout a person's life is an on-going process starting at conception. "As we age, our intelligences simply become more internalized. We continue to think differently from one another and, indeed, differences in modes or mental representation are likely to increase throughout our active life" (Gardner, 1999, p. 112). This critical issue, as stated by Gardner, represents, in many ways, the opportunity to enhance student management and human intelligence skills through community service experiences.

\section{Functions of Management}

According to Ghillyer (2012), "management is the process of deciding the best way to use an organization's resources to produce goods or provide services" (p.4). Management tasks can be divided into several functions, including planning, organizing, leading, controlling, and staffing. Whether an organization is a oneperson business or a multinational corporation, managers use various multiple intelligences to realize the vision, mission, and goals of the organization. There are several ways in which students may also enhance their management and human intelligence skills when involved in community service organizational activities, such as:

\section{Planning}

Planning involves setting goals, deciding on the courses of action to attain the organization's goals, establishing policies and procedures, and developing and forecasting plans. All of these activities are integral to effective planning. Students involved in planning activities for community service organizations may sharpen their management and human intelligence skills by working with organizational stakeholders to establish goals, such as achieving fundraising benchmarks to provide educational scholarships for those in need and developing budgets and creating strategic plans to ensure the viability of the organization's service projects on both a short-term and longterm basis. These activities give students the opportunity to embellish their management and interpersonal human intelligence skills to understand people, relate, share, and participate in cooperative team environments. The conceptual skills required in the planning process will also help students gain greater insight regarding the organizational work atmosphere and how to make effective decisions on the use of the organizations resources. 


\section{Organizing}

Organizing requires establishing tasks to be accomplished, assigning individuals to perform activities, solidifying a chain of command, and coordinating the work of organizational members. An organization that is not organized will certainly be woefully challenged with achieving its vision, mission, goals, and objectives. This applies equally to all types of organizations, public and private, large and small, to include community service organizations. Students involved in organizing activities for community service organizations have the opportunity to sharpen their management and human intelligence skills by teaming with organizational members to develop and implement viable community service projects, such as feeding the homeless and partnering with external stakeholders, such as local and state governments, to initiate early childhood education projects. Participation in such activities broadens the student's verbal-linguistic human intelligence ability and human relations management skills as they become more proficient with the capacity to communicate effectively in writing, memorizing names, places, dates and detailed information, and getting their point across to others. Embodying these skills is a plus in any organization and is necessary to maintain efficiency in community service organizations whereby its members are often volunteering their valuable time and energy in support of the ideals of the community service organization.

\section{Leading}

Leading is "a social influence. It means leaving a mark. It is initiating and guiding, and the result is change" (Manning and Curtis, 2012, p.2). Leading entails empowering others to perform a task that will contribute to the organization's success. Effectively leading others requires a plethora of actions, including the ability to motivate employees, communicate effectively, create cohesive teams, and implement changes required to improve the organization's performance. Leading is an on-going process as the leader's guidance is based on the leader's values, the task that must be accomplished, the members' skill levels, and the organization's culture. Students involved in leading activities for community service organizations may do so by holding regular organizational meetings where the lines of communication are open and its members inquire about their scope of responsibilities and related project details. In such instances, students have the opportunity to sharpen their management and intrapersonal human intelligence skills, such as following personal instincts to effectively direct, counsel, and motivate other members with an unwavering focus of satisfying the high purpose of its members and the organization's goals.

\section{Controlling}

Controlling requires setting standards, measuring how the organization performs to these standards, and taking corrective action if the standards are not met. While budgets, financial statements, time clocks, and other traditional control tools are used to keep control of the firm, using management skills, such as fostering people-first values, encouraging extensive two-way communication, and building a sense of community, is an effective approach and engenders commitment. Committed employees demonstrate self-control, as their companies' mission is considered their own. Thus, committed organizational members who exercise self-control view their organizational contributions as if they were the sole proprietor or they "own" the organization. Furthermore, students involved in controlling activities for community service organizations will have the opportunity to expand their management and logical-mathematical human intelligence skills when working with numbers and engaging in higher order thinking. For example, students who are involved in the financial aspects of community service organization projects may use financial statements and/or budgets to measure how the organization performs financially on service projects coupled with using an integration of management skills, such as encouraging extensive and effective two-way communication and reinforcing the organization's culture of shared values.

\section{Staffing}

Staffing is a significant organizational process which has an impact on the organization's success or lack thereof. "The goal of staffing is to obtain the best available people for the organization and to develop the skills and abilities of those people" (Ghillyer, 2012, p.172). Attracting the best available people is a huge opportunity for any organization as its members are the most valuable asset. While many organizations attract the best available people through a formal recruitment and a hiring process, the organization's brand image also plays a key role for attracting 
potential employees or members. Unlike most corporations, local governments, and colleges, community service organizations are comprised primarily of members that volunteer their knowledge and skills. Thus, staffing for community service organizations is unique in its ability to attract potential members who share and support similar values of the organization and are willing to contribute their expertise and skills without compensation. Students involved in staffing or membership activities for community service organizations may enhance their management and bodily-kinesthetic human intelligences skills by implementing viable community service projects that ignite their passion and caring attitudes, and others resulting in solidifying and increasing membership attraction. For example, students who participate in domestic and/or international hands-on learning projects, such as traveling to other countries to eradicate polio or working with members on a local environmental clean-up project, are using their body movements in learning and expressing while performing a task.

\section{SUMMARY: APPLICATIONS OF MANAGEMENT AND HUMAN INTELLIGENCE SKILLS THROUGH COMMUNITY SERVICE}

Effective implementation of management functions, which include planning, organizing, leading, controlling, and staffing, is necessary for developing and sustaining a healthy and productive organization. Healthy and productive organizations foster a climate that encourages member empowerment, retention, and recruitment which contribute to its longevity and success. Students who are actively involved in community service organizations enhance their management and human intelligences skills by developing and carrying out organizational plans to increase its member base, implementing successful service projects that address the needs of the community, and supporting the organization through both financial contributions and member participation. Thus, application of the management functions within the community service organizational environment gives students an opportunity to enhance their learning, problem solving, and decision making management skills from an operational and human intelligence perspective.

\section{AUTHOR INFORMATION}

Dr. Stefanie Denise Wilson is an associate professor of Business Administration at the University of Hawaii-West $\mathrm{O}$ 'ahu. She earned her Bachelor of Science degree in Business Management from Hampton University, Master's degree in Business Administration with specializations in International Business and Marketing from the University of Miami, and Doctor of Management degree in Organizational Leadership from the University of Phoenix. In addition to teaching, Wilson has always been fascinated with human intelligences, organizational dynamics, and leadership. Her research and publication efforts expand on Howard Gardner's "Theory of Multiple Intelligences" by providing new ways to think about leadership. E-mail: sdwilson@ @awaii.edu

\section{REFERENCES}

1. $\quad$ Ackerman, P. L. \& Lohman, D. F. (2003). Education and g. New York: Pergamon.

2. Gardner, H. (1993). Multiple intelligences: The theory in practice. New York: BasicBooks.

3. Gardner, H. (1983). Frames of Mind. New York: BasicBooks.

4. Gardner, H. (1995, September 15). A cognitive view of leadership. Retrieved April 6, 2003, from EBSCO

Webite: http://web15.epnet.com/citation.asp?tb=1\& ug=dbs+0\%2C1\%2C2\%2C3\%2C5+In+en\%2D

5. Gardner, H. (1999). Intelligence reframed. New York, NY: BasicBooks.

6. Ghillyer, A. (2012). Management Now $2^{\text {nd }}$ Edition, New York, New York, Mc Graw-Hill

7. Manning, G. and Curtis, K.. (2012). The Art of Leadership. (4 ${ }^{\text {th }}$ ed.). New York, NY: McGraw-Hill

8. Riggio, R.E., Murphy, S.E. \& Pirozzolo, F. (2002). Multiple intelligences and leadership. Mahwah, NJ: Lawrence Erlbaum Associates, Inc.

9. Stanford, P. (2003, November). Multiple intelligence for every classroom. Retrieved October 20, 2003, from EBSCO Database:

10. Sternberg, R.J., Grigorenko, E.L. (2003). The psychology of abilities, competencies, and expertise. New York: Cambridge University Press.

11. Wilson, S. D., (2005). The relationship between leadership and domains of multiple intelligences. UMI Microform Num: 3151206. ProQuest Information and Learning Company. 